\title{
Le Ton Stendhal, textes rassemblés et présentés par Philippe Jousset
}

\author{
Michel Arrous
}

\section{(2) OpenEdition \\ 1 Journals}

\section{Édition électronique}

URL : http://journals.openedition.org/studifrancesi/6002

DOI : 10.4000/studifrancesi.6002

ISSN : 2421-5856

Éditeur

Rosenberg \& Sellier

\section{Édition imprimée}

Date de publication : 1 mai 2011

Pagination : 184-185

ISSN : 0039-2944

\section{Référence électronique}

Michel Arrous, "Le Ton Stendhal, textes rassemblés et présentés par Philippe Jousset 》, Studi Francesi [En ligne], 163 (LV | I) | 2011, mis en ligne le 30 novembre 2015, consulté le 13 janvier 2021. URL :

http://journals.openedition.org/studifrancesi/6002 ; DOI : https://doi.org/10.4000/studifrancesi.6002

Ce document a été généré automatiquement le 13 janvier 2021.

\section{(c) (1) (9)}

Studi Francesi è distribuita con Licenza Creative Commons Attribuzione - Non commerciale - Non opere derivate 4.0 Internazionale. 


\title{
Le Ton Stendhal, textes rassemblés et présentés par Philippe Jousset
}

\author{
Michel Arrous
}

\section{RÉFÉRENCE}

Aa. Vv., Le Ton Stendhal, textes rassemblés et présentés par Philippe JousSET, Grenoble, ELLUG, « Recherches et Travaux » 2009, pp. 191.

1 Ton Stendhal ou ton de Stendhal? Vient aussitôt à l'esprit la formule de Valéry: «Ce qui frappe le plus dans une page de Stendhal, ce qui sur-le-champ le dénonce, attache ou irrite l'esprit, - c'est le ton». Cette notion floue a fait l'objet d'une journée d'étude (Grenoble III, juin 2007) dont les communications d'une rare densité sont réunies dans ce volume qui s'ajoute fort heureusement au travail collectif sur Stendhal et le style (Ph. Berthier et É. Bordas éd., Presses Sorbonne Nouvelle, 2005).

2 Dans son introduction Le ton Stendhal: postures, allures, textures (pp. 6-21), Philippe JOUSSET expose deux objectifs liés: en visant Stendhal, définir la notion trop souvent imprécise de «ton» et son usage habituel, usage qui implique d'autres acceptions à la fois sémantiques et sonores, comme «air», «accent», «nuance» ou «voix». On a beaucoup parlé du style de Stendhal - qui en aurait manqué ou qui passe pour ne pas en avoir - ou d'un ton qu'on retrouve aussi bien dans le roman que dans le journal ou l'autobiographie, marque évidente d'une présence dans le discours. Pour Valéry, Stendhal écrivait "comme on parle», ou mieux: "presque comme on se parle»; le ton serait donc un indice de sincérité, mais d'une sincérité ambiguë. Ce désir de «faire vrai» qu'on décèle dans le ton de Stendhal doit être appréhendé d'un point de vue stylistique, rhétorique et sociologique, à la fois comme modalité de langage et comme conduite. Un exemple est donné par Philippe JOUSSET lui-même dans L'économie du ton. Réflexions à partir des premières pages de "Lucien Leuwen" (pp. 49-67): dans les trois brefs premiers chapitres du roman, la voix du narrateur affirme sa personnalité et recherche la complicité du lecteur, que le narrateur s'affiche ou s'efface - non sans le faire 
remarquer. L'exemple choisi permet de comprendre que «le ton est un aspect du style, une de ses dimensions, celle qui envisage le style dans son rapport à une présence déléguée à une voix». Dans Le ton du texte: une aporie poétique (pp. 25-36), François VANOOSTHUYSE rappelle que la notion de voix est une métaphore dont on ne peut se passer, comme le montre son analyse de la complexité du «sémantisme sonore» de l'ouverture de la Vie de Napoléon. Partant de la notion acoustique et musicale de ton et de tonalité, Éric BORDAS mesure l'originalité du style dès la première phrase des romans de Stendhal, en regard avec d'autres débuts chez ses contemporains (Mme de Duras, Latouche, Balzac, Hugo, Sand): En majeur ou en mineur? Tonalités et modalités des incipit romanesques stendhaliens (pp. 37-47). Si l'ironie stylistique, qui est toujours une remise en question, n'est pas rare à l'époque, chez Stendhal elle se distingue par sa concision et son individuation. Avec Les tilleuls du ministère de la Guerre (pp. 69-77), Karin GUNDERSEN évoque son expérience de traductrice chevronnée de Stendhal à la recherche et au rendu du ton, expérience qu'elle illustre avec le début du chapitre 14 de la Vie de Henry Brulard où règne le ton de la conversation.

3 La deuxième partie du recueil est consacrée à l'individualité du discours stendhalien dans le roman. Agathe NOVAK-CHEVALIER (Le ton du roman stendhalien: un anti-théâtre?, pp. 81-93) aborde la question du choix du ton déterminant à la fois chaque personnage et la posture anticonformiste adoptée par l'écrivain. Dans «Le ton le plus individuel qui soit en littérature». De la singularité sublime à l'efficacité rhétorique (pp. 95-107), de Marie PARMENTIER, on retrouve la qualité des subtiles analyses de son Stendhal stratège pour l'examen des tonalités qui étrangement coexistent dans la narration stendhalienne: le bon ton, l'ironie, les interventions du narrateur en «pédagogue supérieur» à qui il arrive de se désolidariser, souvent d'une manière feinte, de son personnage. Laure LASSAGNE (Ton du discours intérieur dans les romans de Stendhal, pp. 109-120) se propose d'appréhender le ton des nombreux monologues par le biais de l'articulation logique entre les segments langagiers, articulation que caractériserait une hypertension logicosyntaxique.

La troisième partie s'ouvre par une plaisante et très convaincante communication consacrée à Stendhal fantastiqueur (pp.123-141), dans laquelle Daniel SANGSUE montre que le fantastique chez Stendhal n'est pas seulement affaire de thèmes, mais aussi de ton. En parfait incrédule, Stendhal s'intéresse moins aux histoires de revenants qu'à l'horreur, alors à la mode, comme ressource littéraire. Ce qui le préoccupe - dans, par exemple, Le Coffre et le revenant, parodie où il joue avec les poncifs du fantastique - ce sont les dispositifs narratifs et rhétoriques marqués au signe du déceptif. Une petite analyse «fantomologique» d'Armance montre que c'est aussi le cas de ce roman «truffé» de motifs fantastiques, mais dans ce cas sérieusement traités. De même dans Le Rouge et le Noir (le séminaire, Mathilde dans l'évêché de Besançon, les fantômes que croit apercevoir Julien, etc...) ou dans San Francesco a Ripa. Chez Stendhal, il y a bon nombre de morts vivants bien réels, et ces figures auraient à voir avec la «fantomologie» familiale des Beyle. Henri Beyle premier resurgit! Georges KLIEBENSTEIN, dans Stendhal et le scandale tonal: le déton(n)ant et le bêlant (pp. 142-170), revient sur l'impossible réduction à l'unité de la notion de ton - scriptural, vocal, théâtral, social, musical - et sa singularité chez Stendhal. On voit comment, à partir de l'exemple de quelques scènes dans Lucien Leuwen (Lucien face au comte de Beausobre ou face au préfet Séranville), un changement de ton entraîne un basculement, et combien est complexe la parabole du coup de pistolet, ce «couac» qui signifierait la mort de la littérature, du lecteur et du 
littérateur. Dans Le mauvais ton de Stendhal. Les comptes rendus du "Rouge et le Noir" en 1830-1831 (pp.171-179), Pierre LAFORGUE examine la réaction idéologique de la plupart des contemporains de Stendhal qui, identifiant l'un à l'autre, ont jugé le style et l'auteur du Rouge non sans parfois frôler la haine (voir le cas de Jules Janin). Stendhal homme d'esprit, «ami des paradoxes», et surtout «désenchanteur»: "cela revient à dénoncer chez lui une attitude qui détone». Ce volume d'actes se clôt sur une exclamation que Georges MATHIEU a empruntée à V. Del Litto: Stendhal pornographe! (pp. 181-191). Peut-on retrouver le «ton stendhalien» dans Les Écrits érotiques de Stendhal (1928) constitués de «quelques passages obscènes, graveleux, à dominante satirique», parfois en langage technique par souci de provocation et écrits le plus souvent au courant de la plume? Quand on sait que Stendhal avait en horreur les propos libertins français, la question a de quoi surprendre. G. Mathieu signale le vocabulaire classique et "assez limité», de récits dont la sécheresse contraste bien évidemment avec la luxuriance ou le lyrisme érotique de Nerciat, Mirabeau, etc... 